\title{
Administrando o imensurável: uma crítica às organizações acadêmicas
}

\author{
Administering the immeasurable: a critique of academic organizations
}

Victor Meyer Júnior ${ }^{1}$

Maria Cecilia Barbosa Lopes ${ }^{2}$

\section{Resumo}

Este ensaio teórico focaliza temas concernentes à administração das universidades. Os ensaístas refletem sobre o papel do administrador universitário, oferecendo críticas à utilização de modelos empresariais que não observam as características e complexidade das organizações acadêmicas. De um lado, os autores criticam a utilização de abordagens gerenciais racionais com excessivo foco na eficiência e em elementos mensuráveis, desconsiderando princípios e valores essenciais à natureza das organizações acadêmicas. Por outro lado, destaca-se a inexistência de modelos e teorias administrativas prontas, que atendam às especificidades dessas organizações. Os ensaístas lembram que a teoria da administração universitária ainda está em formação, com base em estudos científicos e na análise de boas práticas observadas em instituições de Ensino Superior. Conclui-se que há necessidade de adoção de uma prática gerencial que privilegie diversas dimensões de caráter objetivo e, principalmente, de caráter subjetivo, notoriamente de difícil mensuração e que integram a essência do trabalho acadêmico. A adoção de tais práticas exige administradores capazes de integrar técnica e arte, racionalidade e intuição.

Palavras-chave: Universidades. Administração. Organizações acadêmicas. Mensuração.

\begin{abstract}
This theoretical essay focuses on themes concerning the administration of universities. The essayists think through the university administrator's role, offering some criticism on the use of business models that do not observe the characteristics and complexity of academic organizations. On the one hand, the authors criticize the use of rational managerial approaches with an excessive focus on effectiveness and measurable elements, disregarding principles and values that are crucial to the nature of academic organizations. On the other hand, the authors highlight the absence of ready-made administrative models and theories, which meet the specificities of these organizations. The essayists remind that the theory of university administration is still under development, it is based on scientific studies and the analysis of good practices observed in Higher Education institutions. The authors conclude that there is a need for adopting a managerial practice that favors various dimensions with an objective nature and, especially, with a subjective nature, which are known to be difficult to measure and included into the essence of academic work. The adoption of such practices requires administrators who are able to combine technique and art, rationality and intuition.
\end{abstract}

Keywords: Universities. Administration. Academic organizations. Measurement.

Artigo submetido em 5 de março de 2014 e aceito para publicação em 18 de julho de 2014.

DOI: http://dx.doi.org/10.1590/1679-395117485

${ }^{1}$ Doutor em Administração Universitária pela University of Houston, EUA; Professor e pesquisador do Programa de Pós-Graduação em Administração pela Escola de Negócios, Pontifícia Universidade Católica do Paraná. Endereço: Rua Imaculada Conceição, 1155, CEP 80215-901, Curitiba-PR, Brasil. E-mail: victormeyerir@gmail.com

2 Doutora em Educação pela Pontifícia Universidade Católica do Rio Grande do Sul; Técnica de Assuntos Educacionais pela Universidade Federal do Paraná. Endereço: Praça Santos Andrade, Centro, CEP 80060-000, Curitiba-PR, Brasil. E-mail: mariaceciliabarbosalopes@yahoo.com.br 


\section{Introdução}

Atualmente, não faltam teorias no campo da Administração e essa expansão de conceitos, modelos e teorias já tem causado certa preocupação entre os que se dedicam ao estudo das organizações. Lapierre (2005) destaca que, hoje, todas as organizações, sejam públicas ou privadas, inclusive as organizações do terceiro setor, como aquelas que atuam nos campos educacional, cultural e até religioso, são examinadas por meio de princípios, teorias e modelos de Gestão. O autor lembra que, no espaço de poucas décadas, a Administração se tornou uma nova referência universal e, nos dias atuais, todas as atividades humanas são medidas por seus padrões. Somos permanentemente encorajados a pensar em nossos colegas, chefes e até em membros de nossa família como clientes e parceiros, cujas necessidades devem ser atendidas.

Se, de um lado, os estudos e teorias da Administração se expandem, de outro, também crescem as críticas ao uso indiscriminado de tais modelos e, em especial, ao uso de teorias herméticas, algumas baseadas em modelos matemáticos, inadequadamente importadas de outras áreas do conhecimento, como, por exemplo, da Física ou Biologia. Ghoshal (2005), um desses críticos, destaca que muitas teorias são baseadas em ideologias e suposições falsas acerca de pessoas e instituições e negam o papel das escolhas e intenções humanas. Aplicadas ao mundo real, tornam-se profecias autorrealizadoras, destruindo boas práticas. Ainda segundo o autor, nada é mais perigoso que uma teoria ruim.

As críticas não se restringem às novas abordagens na área da Gestão, elas também atingem a formação dos gestores. Mintzberg (2004) afirma que os cursos de mestrado em Administração treinam as pessoas erradas, do modo errado, gerando as consequências erradas. Programas desse tipo têm por foco pessoas jovens, com pouca experiência em Administração e enfatizam técnicas analíticas, desconsiderando o aprendizado focado na prática.

Neste artigo é trazido para discussão um tema que tem desafiado a administração das organizações acadêmicas ao longo dos anos e que foi esquecido ou não recebeu a devida atenção daqueles que se dedicam ao estudo e ao enfrentamento de questões relevantes da administração educacional.

Inicialmente, há uma reflexão acerca do papel do administrador universitário, com críticas à utilização de modelos gerenciais oriundos do setor empresarial, uma prática considerada inadequada, visto que há incompatibilidade entre a racionalidade implícita nessas abordagens e as características peculiares e únicas que incluem as instituições acadêmicas entre as mais complexas organizações sociais.

São criticadas as abordagens gerenciais empresariais adotadas por seu foco excessivo na eficiência e, portanto, em elementos mensuráveis, consequência de uma cultura managerialista, predominante na literatura da área da Administração e disseminada no mundo capitalista. Essa cultura privilegia essencialmente a racionalidade econômica e idolatra o mercado, em detrimento de valores igualmente importantes que permeiam a vida acadêmica e que estão implícitos em sua missão: promover o conhecimento e a aprendizagem inspirados em princípios éticos, visando à formação de pessoas, preparandoas para a vida em sociedade. Esses valores não podem ser negligenciados, sob pena das universidades abandonarem sua principal missão e essência.

Acredita-se que um dos maiores desafios dos administradores universitários é a adoção de uma gestão que envolva múltiplas variáveis decorrentes de sua complexidade, em especial aquelas de caráter subjetivo e de difícil mensuração. Tal administração exige administradores capazes de combinar, em suas práticas, arte e ciência, racionalidade e intuição, criatividade e inovação, com coragem e sensibilidade suficientes para tomar decisões que não necessariamente encontram respaldo nos modelos racionais importados do setor empresarial. 


\section{Administração das Universidades}

Tradicionalmente, o papel da Administração tem sido o de tornar produtivos os recursos de uma organização, possibilitando o cumprimento de objetivos e metas, assim como satisfazendo as expectativas dos stakeholders. Nesse papel, os gestores, em suas práticas, utilizam racionalidade e técnica, assim como intuição e criatividade, o que faz com que a Administração seja considerada, ao mesmo tempo, uma ciência e uma arte.

Para Birnbaum (1989), a ciência está voltada ao entendimento da estrutura, das programações, dos sistemas e do poder de uma organização e, assim, os administradores devem coletar e analisar informações, avaliar relações, inferir causalidade e gerar e testar hipóteses, desenvolvendo teorias probabilísticas a respeito de causa e efeito.

Como arte, ressalta o mesmo autor, a Administração é influenciada pela sensibilidade, pela expertise e pela intuição e, nesse papel, o administrador é um artista que procura criar novas realidades e influenciar os outros, na medida em que cria novos ambientes. Na concepção de Birnbaum (1989), o ideal seria que o administrador reunisse os dois papéis, integrando o pensar e o agir.

Nem todos os teóricos da Administração, no entanto, pensam da mesma forma. Para Mintzberg (2009), por exemplo, Administração não é ciência nem profissão, é, em essência, uma prática adquirida por meio da experiência e enraizada no contexto. Assim, a Administração não é ciência aplicada, ela simplesmente aplica a ciência. Pouco da prática gerencial pode ser codificada de maneira confiável, certificando sua eficácia (MINTZBERG, 2009).

É difícil definir claramente as funções de um administrador na sociedade contemporânea. Mais difícil ainda é analisar o real papel que vem sendo desempenhado pelos administradores universitários. Isso porque, no caso das universidades, seus administradores enfrentam desafios que estão relacionados à natureza complexa dessas organizações e que dificultam tanto a prática gerencial como o desempenho organizacional. Esforços têm sido feitos para identificar as características e especificidades das universidades, tratando-as como burocracias profissionais (MINTZBERG, 1994), sistema político (BALDRIDGE, 1971), anarquia organizada (COHEN e MARCH, 1974) e sistema frouxamente articulado (WEICK, 1976).

Um olhar mais acurado identificará no interior das organizações universitárias alguns elementos relevantes que escapam ao olhar desavisado, como ambiguidade dos objetivos, tecnologia indefinida, grupos de interesse, poder compartilhado e a imensurabilidade do valor agregado. Esses elementos dispersos, porém, inter-relacionados, contribuem para a complexidade organizacional das universidades, constituindo, ao mesmo tempo, barreiras às práticas gerenciais tradicionais.

O interesse pela administração das organizações educacionais tem oscilado ao longo do tempo. Há um pressuposto, compartilhado pelo senso comum, de que a administração desempenha papel importante no funcionamento das organizações, em especial quanto ao uso adequado dos recursos como forma de oferecer serviços educacionais relevantes à sociedade. O pressuposto, seguindo a abordagem clássica e racional, é que a administração constitui a força motriz que faz com que objetivos, decisões, ações e resultados estejam alinhados da forma mais eficiente e eficaz.

Tem sido comum a comparação entre universidades e empresas, uma vez que grande parte das abordagens gerenciais, disseminadas nas universidades, foi modelada para o contexto empresarial. A ênfase na importação de ferramentas gerenciais aplicadas ao segmento universitário - managerialismo - pressupõe semelhanças entre as duas formas de organização.

Para Stacey (2010), as escolas de administração de empresas têm sido responsáveis por disseminar princípios inspirados no capitalismo liberal e representado por abordagens racionais e reducionistas que buscam a máxima eficiência e lucratividade. 
A institucionalização dessas práticas nas universidades pode ser atribuída à influência dos modismos gerenciais e ao papel dos consultores ao qual se refere Birnbaum (2000), bem como ao isomorfismo (MEYER e ROWAN, 1977) decorrente de tais influências.

Mais recentemente, a transformação de universidades em empresas educacionais intensificou essa prática. O corolário da Administração traz a ideia de que princípios comuns regulam as atividades em qualquer tipo de organização, cabendo aos gestores fazer os ajustes necessários às peculiaridades e ao contexto organizacional.

De acordo com essa concepção, o desempenho e o sucesso de uma organização acadêmica são atribuídos à qualidade de sua administração, ou seja, quanto melhor for a administração, melhor será o desempenho organizacional, seguindo a lógica da administração empresarial, predominante na literatura. Contudo, no entendimento de Birnbaum (1989), a administração e o desempenho nas organizações universitárias não estão direta e necessariamente relacionados. Ao contrário, como destaca o autor, as universidades são bemsucedidas exatamente porque não têm uma boa administração, ou seja, uma melhoria na administração significaria uma perda da eficácia organizacional. Conceitos como eficiência e eficácia implicam um tradeoff, ou seja, avanços em uma delas resulta em recuos na outra. Assim, salas de aula repletas de alunos, atingindo a capacidade máxima, podem representar grande eficiência. Contudo, tal eficiência poderá indicar perdas consideráveis sob a ótica do aprendizado e da eficácia organizacionais.

Ao se referir à administração universitária, Simon (1967), em tom provocativo, comenta que as instituições de Ensino Superior formam profissionais e são dirigidas por amadores. Percebe-se o paradoxo da afirmação. No contexto brasileiro, a forma como são selecionados os gestores universitários, com critérios essencialmente políticos e subjetivos, reforça essa percepção.

Os administradores universitários, em sua esmagadora maioria, desconhecem ou não se atêm às peculiaridades das universidades em suas práticas gerenciais. Como consequência, esses administradores têm manifestado um comportamento duplamente inadequado. Primeiro porque, devido ao desconhecimento, não aplicam o conjunto de pressupostos que caracterizariam uma ciência; e, segundo, porque tampouco recorrem à arte, já que não têm buscado soluções inovadoras e criativas para os problemas organizacionais, valendo-se de soluções oriundas do setor empresarial e, portanto idealizadas para outro contexto.

É importante ressaltar que não existem teorias prontas para ser aplicadas ao ambiente universitário. As teorias exigem uma grande sensibilidade dos administradores para ajustar métodos, abordagens e práticas às especificidades das organizações acadêmicas. Como já destacava Keller (1983), a teoria da administração universitária está em formação, com base em estudos científicos e em boas práticas administrativas nas instituições de Ensino Superior.

O fato é que as características especiais das universidades, que as diferenciam de outros tipos de organização, como as empresas e as agências governamentais, fazem com que o funcionamento de uma organização universitária se distancie de outras realidades organizacionais, exigindo, por consequência, abordagens próprias, ainda não disponíveis.

Dentro desse enfoque, qual seria, então, o papel da administração universitária? Cabe à gestão a tarefa precípua de promover, com liderança e autoridade, a aprendizagem, a produção do conhecimento e as ações comunitárias. Externamente, o Ensino Superior, em função da sua relevância social, é um setor altamente regulamentado, sendo uma das responsabilidades da administração das instituições prestar contas à sociedade a respeito dos recursos utilizados e da qualidade dos serviços educacionais prestados. Internamente, cabe a esse administrador supervisionar, conduzir e mediar uma comunidade extremamente heterogênea de professores, alunos e funcionários, agrupados em unidades acadêmicas quase autônomas, o que levou Weick (1976) a denominá-la um "sistema frouxamente articulado". 


\section{O que agrega a administração universitária?}

Um dos grandes desafios da administração na universidade tem sido o exame de seu desempenho como organização prestadora de serviços. Primeiro, porque a universidade se propõe a atender a uma infinita diversidade de expectativas de seus alunos, de seus professores e, também, da comunidade externa. Segundo, pela natureza qualitativa e dinâmica dessas expectativas e preferências. Terceiro, pelo fato da natureza do trabalho acadêmico não comportar uniformidade e padronizações de procedimentos, em vista das individualidades envolvidas no processo de ensino-aprendizagem e no processo de produção do conhecimento. Todos esses elementos impedem a existência de uma métrica que possibilite avaliar com maior precisão os resultados organizacionais e a tudo isso se somam os complexos conceitos de qualidade e relevância social.

O que se vem observando, nos últimos vinte anos, é um crescente interesse e concentração de esforços com o objetivo de elevar o desempenho das instituições de Ensino Superior e, particularmente, das universidades. Três razões podem ser identificadas como decorrentes dessa tendência: 1) o grande o volume de recursos utilizados por essas instituições; 2) as políticas públicas que objetivam adaptar o sistema de Ensino Superior às necessidades econômicas e sociais da nação; e 3) a crescente competição entre as universidades, em especial no setor privado, com a entrada nesse mercado das universidades empresariais. Essas demandas têm motivado, entre os administradores das universidades, a incorporação de abordagens da administração de empresas, com o objetivo de melhorar o desempenho organizacional e a imagem institucional.

Nesse sentido, tem sido comum o esforço de associar resultados e objetivos educacionais, mas nem sempre esses dois conceitos estão alinhados. Como já destacado, as instituições de Ensino Superior são conhecidas por seus objetivos ambíguos e tecnologia complexa. Essa ambiguidade permite interpretações múltiplas e, consequentemente, conduz a uma variedade de equívocos relacionados às decisões, aos processos, às ações e, também, aos resultados obtidos pela organização.

Tem causado preocupação o foco excessivo na eficiência, embora se reconheça que alguma medida de eficiência seja necessária em qualquer organização. Ocorre, no entanto, que, ao enfatizar a eficiência, os administradores têm negligenciado a eficácia das organizações acadêmicas. Isso decorre, principalmente, do fato de ser mais fácil tomar decisões baseadas em elementos mensuráveis, de fácil observação, variáveis que a cultura capitalista ocidental tende a considerar verdades absolutas e, portanto, "inquestionáveis".

Mesmo as medidas numéricas utilizadas para avaliar a eficiência têm escopo limitado por se concentrar nos custos e desprezar os benefícios. Frequentes medições de eficiência conduzem a uma concentração na produção de elementos que possam ser mensurados, negligenciando aqueles de maior dificuldade de mensuração. É mais fácil contar o número de alunos formados ou o número de aulas ministradas pelos professores que o conhecimento adquirido por esses alunos em determinado semestre, assim como é mais fácil contabilizar o número de artigos acadêmicos produzidos que o impacto de determinado conhecimento científico na sociedade.

Diferentemente de empresas industriais ou agrícolas, cuja produção se concentra em bens tangíveis, a produção acadêmica abrange insumos, transformação e produtos de natureza intangível. São conceitos, ideias, técnicas, habilidades e conhecimento que não podem ser mensurados por indicadores quantitativos. Muitas vezes, o impacto dos produtos resultantes do processo acadêmico só é percebido como influente ou relevante muito tempo após sua absorção pelos indivíduos beneficiados pelo sistema educacional.

É preciso que se reconheça que, muitas vezes, é impossível ou impraticável quantificar os resultados centrais e substantivos de uma organização. Do mesmo modo, deve-se destacar que a ineficiência é, muitas vezes, necessária como espaço para inovação, criatividade e melhoria (BOULDING, 1978).

Outro autor que crítica a ênfase na eficiência é Mintzberg (1989). O autor ressalta que "eficiência", na administração das organizações, é considerada uma "má palavra", em razão de seu uso. Eficiência é um 
construto essencialmente econômico que, na prática, não significa obter o maior benefício em relação ao custo, mas, sim, obter o maior benefício mensurável por custo mensurável.

Para Mintzberg (1989), a obsessão com eficiência significa privilegiar benefícios tangíveis e mensuráveis, negligenciando benefícios menos visíveis e quantificáveis. Aliás, muitos anos antes desse autor, Etzioni (1964) já advertia que aspectos superficiais dos resultados de uma instituição são, em geral, mais facilmente mensuráveis que aqueles mais substantivos.

Merece destaque, também, o pensamento do prof. James Heckman, prêmio Nobel de Economia e defensor de políticas de qualidade para a primeira infância como forma de reduzir a desigualdade. Para ele, as escolas, ao ser pressionadas pelos testes que medem o desempenho dos alunos, tendem a se concentrar em leitura e Matemática, desconsiderando aspectos mais relevantes para o desenvolvimento intelectual e humano, como a motivação, o controle emocional e a interação social (GOIS, 2011, p. A12).

Embora o foco e referência tenham sido a escola básica, o mesmo comentário pode ser estendido às instituições de Ensino Superior, que se concentram na formação profissional em detrimento de uma formação mais eclética, onde elementos como ética, valores sociais, motivação, interação e controle emocional têm, no mínimo, igual importância na formação dos alunos.

No que se refere às universidades, sua natureza complexa e o fato de suas atividades serem essencialmente voltadas à aprendizagem, portanto, qualitativas, tornam a medição de sua eficiência e eficácia uma tarefa quase inexequível. Ao abordar a questão da eficiência nas universidades, Bowen (1980) aponta duas falácias: a primeira é o fato de examinar a eficiência considerando apenas custos, por exemplo, custo-aluno/ano. $\mathrm{O}$ pressuposto, nesse caso, é que quanto mais baixo o custo, mais eficiente seria a universidade. A segunda falácia é julgar a eficiência somente em relação aos resultados, ou seja, os ganhos em resultados são desejados independentemente de seus custos. O problema, segundo o autor, é que essas abordagens falham em reconhecer que eficiência é sempre uma relação entre duas variáveis: custo e resultado. Este autor lembra que o Ensino Superior trata, em sua essência, da dimensão intelectual, da personalidade e de valores, os quais não podem ser medidos, de forma rigorosamente quantificável, em unidades monetárias ou em taxas de retorno.

A avaliação dos diversos resultados do Ensino Superior apresenta dificuldades conceituais e metodológicas. Para Bowen (1980) o Ensino Superior gera benefícios individuais e sociais e sua avaliação constitui muito mais que uma técnica, ela envolve, na verdade, uma arte.

Dentre os benefícios individuais, o autor destaca a aprendizagem cognitiva, o desenvolvimento emocional e moral, a competência prática (traços de valores e cidadania) e a satisfação e o desfrute da educação universitária (durante o período e ao longo da vida). Entre os benefícios sociais são destacados o avanço do conhecimento, as descobertas e o desenvolvimento de talentos e as melhorias do bem-estar social (nos aspectos econômicos, na solução de problemas sociais, no fortalecimento do prestígio nacional, na melhoria dos valores, das aspirações e das atitudes de membros da sociedade), além de outros benefícios desenvolvidos ao longo do tempo, nos campos da cultural, justiça, segurança, ordem, religião, saúde, liberdade e no fortalecimento das relações sociais.

Mais recentemente, autores como Bok (2003), Brewer, Gates e Goldman (2002) e Reynolds (2014), ao resumir os benefícios do Ensino Superior, ressaltam três áreas: desenvolvimento de habilidades, prestígio institucional e rede social. São benefícios que, por sua natureza, os indivíduos e a sociedade têm dificuldade de mensurar, pois sua importância pode variar ao longo do tempo.

\section{Medição do esforço acadêmico}

Um das questões centrais da administração universitária é a medição do esforço acadêmico e de seu valor agregado. Trata-se de tarefa complexa, dada a diversidade de elementos qualitativos implícitos no processo de ensinar, pesquisar e aplicar conhecimento, bem como nas práticas dos diversos profissionais responsáveis 
por esse esforço representando o comportamento organizacional nessa área. A análise e medição dessa produção acadêmica são desafiadoras e as métricas existentes não são uniformes, tampouco confiáveis, para possibilitar que os administradores tomem decisões e ajam mais profissionalmente.

Essa medição e seu foco variam de acordo com o tipo de instituição e suas características. Em faculdades, cuja missão institucional que constitui a essência do trabalho está fundamentada na formação de profissionais para o mercado, o ensino é o foco principal da atividade, enquanto em centros universitários a função social também é uma preocupação organizacional. No caso das universidades, observa-se um maior grau de complexidade das atividades, com integração das funções de ensino, pesquisa e serviços à comunidade. No ensino de graduação e pós-graduação, a diversidade de áreas e programas é subjetivamente maior. Observa-se que, conforme aumenta a complexidade das atividades acadêmicas, o esforço de medição também se torna significativamente maior e mais desafiador para os gestores universitários.

Medir o esforço acadêmico é, também, medir a qualidade da educação. Nesse particular, Juliatto (2005) ressalta que a qualidade é conceito multidimensional e multifacetado, abrangendo vários e distintos aspectos das atividades de uma organização educacional. Em alguns casos, observa-se a existência de condições e características que revelam a qualidade, quer no nível institucional, quer no nível dos programas, assim como a ausência dessas características revela a falta de qualidade. $\mathrm{O}$ indicador de qualidade é uma estrutura de informação que só se torna significativa quando conteúdo e número estão associados.

Os rankings das universidades procuram medir a qualidade ou o status de uma instituição com base na percepção de especialistas acerca de fatores como número de doutores, publicações internacionais, detentores de prêmio Nobel, patentes registradas entre outros, classificando-os como indicadores de maior qualidade acadêmica. Há um pressuposto para a avaliação das universidades de que as instituições com professores mais laureados oferecem melhor qualidade de ensino e maior e mais relevante produção acadêmica. Na prática, sabe-se que não se pode estabelecer uma relação de causalidade entre esses elementos e o valor agregado pela instituição aos seus egressos.

Para Cameron (1978), quatro fatores obstaculizam a medição da eficácia e do desempenho de uma instituição de Ensino Superior: 1) a dificuldade de identificar, de forma concreta, objetivos e resultados mensuráveis; 2) o processo de avaliação e medição desencadeia ceticismo e comportamento defensivo na comunidade acadêmica; 3) a preocupação das instituições com as finanças conduz à medição para a eficiência ao invés da eficácia; e, por fim, 4) a estrutura das organizações acadêmicas, definidas por conceitos como "anarquia organizada" ou "sistema frouxamente articulado" e "complexas latas de lixo", estabelecidos, respectivamente, por Cohen e March (1974), Weick (1976) e March e Olsen (1976), dificulta ou até impede a aplicabilidade da eficiência e da eficácia nesse tipo de organização.

Após examinar a realidade de seis instituições universitárias americanas, Cameron (1978) propôs nove dimensões a ser consideradas para medir a eficácia das instituições universitárias: 1) satisfação do aluno com a educação recebida; 2) desenvolvimento acadêmico do estudante; 3) desenvolvimento da carreira do estudante; 4) desenvolvimento pessoal do estudante; 5) satisfação de professores e administradores; 6) desenvolvimento profissional e qualidade do professor; 7) abertura sistêmica e interações com a comunidade; 8) capacidade de atrair recursos; e, por fim, 9) saúde organizacional. Esses elementos de Cameron (1978) são essencialmente qualitativos e, como tais, estão sujeitos às interpretações humanas e temporais, refletindo a dificuldade de, efetivamente, mensurar o valor agregado pelas universidades.

No entendimento de Bowen (1980), avaliar o desempenho do Ensino Superior representa um grande desafio conceitual e metodológico. Os resultados são muito numerosos, inter-relacionados de forma complexa, frequentemente sutis, muitas vezes não intencionados e aleatórios, instáveis ao longo do tempo, com uma essência de difícil identificação e julgados de forma distinta, em momentos distintos, por distintos observadores, tornado-se impossível estabelecer relações de causalidade entre os fatores.

Como já destacado, o conceito de eficiência envolve uma relação de meios e fins. No Ensino Superior, os meios são representados pelo trabalho e capital adquirido com dinheiro. Os fins, por sua vez, são 
representados por inúmeras transformações promovidas nas pessoas sob a forma de conhecimento, motivação, valores e sensibilidade.

\section{O frenesi da mensuração}

Um ditado popular diz que "os números não mentem”, o que significa dizer que se deve medir determinada realidade para conhecê-la. Na vida das pessoas, assim como na das organizações, isso não é necessariamente verdade. Os números, por si, nada revelam, são apenas indicativos de determinada realidade, medida em determinado universo temporal, sempre sujeitos às interpretações dos observadores.

A mensuração nunca é um ato neutro, ela está sujeita ao viés do pesquisador que mensura, seguindo seus mapas cognitivos, suas premissas ou expectativas e intenções, o que faz com que os dados e informações se tornem ambíguos e confusos. Sabe-se que os dados podem oferecer base para uma a descrição, mas quase nunca para a explicação de determinado fenômeno ou realidade. Números são interpretados, transformados em informações que irão subsidiar decisões, influenciar ações e a interpretação de resultados.

Os dados, por sua vez, estão sujeitos a três problemas cruciais, quais sejam: 1) o excesso; 2) a temporalidade; e 3) a confiabilidade. É comum que sistemas de informações gerem uma quantidade muito grande de dados, que acabam sufocando, pelo volume, os profissionais responsáveis por sua análise.

Na gestão das organizações, Langley (1995) se refere a esse fato, denominando-o "paralisia pela análise”. Há uma tendência, de cunho formal racional, de coletar mais informações que as necessárias para as decisões e ações nas organizações. O resultado é a dispersão de foco, com implicações para a decisão, gerando a inação nas organizações. Mensurar tudo o que é passível de mensuração, sem considerar sua importância, é uma clara manifestação dessa patologia organizacional.

Existem dados cuja relevância está associada a determinado contexto temporal e existem dados relacionados a um universo temporal muito restrito. São dados específicos, relacionados a eventos episódicos, que não ocorrem com regularidade e que não podem ser analisados como típicos ou representativos de uma realidade, caso contrário, gerariam decisões e ações distorcidas.

A coleta e o tratamento dos dados são fontes de maior ou menor confiabilidade, e essa confiabilidade é extremamente importante para o tomador de decisão. A imagem de competência da fonte dos dados tem impacto junto aos tomadores de decisão e responsáveis pelas ações organizacionais.

Vive-se em uma sociedade que possui uma verdadeira obsessão pela mensuração. Para alguns, trata-se de uma bênção, enquanto para outros de uma verdadeira praga. Orientados por um frenesi de medição, modelos de avaliação de desempenho são criados, visando a conhecer melhor o sistema, seus processos, resultados e valor agregado. Enquanto no setor empresarial esse tem sido um comportamento comum, no caso das organizações acadêmicas, essas práticas têm encontrado maiores dificuldades de operacionalização. Em muitas organizações pode-se observar uma dissonância estratégica representada por discrepância e não alinhamento entre objetivos, decisões, ações e resultados, o que faz com que a interpretação dos resultados tenha um caráter essencialmente subjetivo e pessoal.

Há, ainda, a dimensão da legitimidade trazida com as práticas de controle nas organizações. Aos olhos dos proprietários, acionistas e outros stakeholders, as organizações necessitam apresentar resultados positivos, de modo a justificar sua existência. No caso das empresas se trata do lucro, enquanto no caso de organizações públicas e organizações do terceiro setor a relevância social e a legitimidade dos serviços se tornam fatores críticos aos olhos da sociedade.

Em organizações sem fins lucrativos, um dos grandes desafios é a medição da eficácia organizacional. Estudo realizado por Forbes (1998) sumariza, em três abordagens não excludentes, as principais práticas utilizadas na medição da eficácia nesse tipo de organização: 1) a abordagem do cumprimento de objetivos, 
que tem por foco o exame da extensão na qual os objetivos organizacionais foram atingidos; 2) a abordagem da captação de recursos, que se refere ao montante de recursos captados e gerenciados pela organização; e, por fim, 3) a abordagem da reputação, que se refere à opinião de pessoas ou grupos-chave, usuários do sistema e grupos profissionais, sobre a organização, seu desempenho e prestígio. Nas universidades, sabe-se que os objetivos são ambíguos, os recursos são sempre insuficientes diante da grandeza da missão e a reputação junto à sociedade está mais centrada em resultados de rankings que no real valor agregado - a transformação das pessoas e a produção de conhecimento.

A maior parte dos modismos gerenciais utilizados na gestão acadêmica enfatiza a quantificação. Alguns vão ao extremo de destacar que se algo não pode ser medido, não pode ter valor (BIRNBAUM, 2000). Não há nada errado em utilizar indicadores numéricos, quando isso é possível. Contudo, é necessário que se tenha consciência de que as relações ou os fenômenos indicados por esses modelos matemáticos não são necessariamente verdadeiros, ou seja, são representações da realidade.

Como adverte Becker (2009), a ciência social, inúmeras vezes, recorre a objetos matemáticos, tipos ideais e parábolas para representar realidades, mas dificilmente qualquer um desses meios de representação vai corresponder plenamente à atividade humana ou à realidade que se pretende observar ou descrever.

Boulding (1978) alerta para o cuidado que se deve ter nas medições numéricas de eficiência, especialmente quando os números não representam uma importante realidade, como em geral acontece. Nem tudo o que se apresenta ao tomador de decisão, em termos de número, são verdades, mas são apenas evidências. Destaca e adverte o autor: "Acreditar que evidência é a verdade é a receita para péssimas decisões. Em universidades, isso poderia ser desastroso" (BOULDING, 1978, p. 48, tradução nossa).

A dificuldade de mensuração e a frustração desencadeiam entre os administradores uma sensação de impotência e de incapacidade para apresentar resultados concretos como faz a maioria das empresas, ao utilizar, na medição, índices conhecidos e consagrados no setor. Assim, ao adotar métodos e práticas assemelhadas para a mensuração do desempenho das instituições de Ensino Superior, em particular as universidades, na verdade, contribui-se para a criação e o fomento de uma verdadeira "ilusão de controle", na qual a essência daquilo que se quer medir e avaliar passa por entre os dedos.

Lembrando as palavras de Nietzsche (2000, p. 276),

[...] se se avaliasse o valor de uma música pelo que se pode calcular e contar, pelo que se pode traduzir em números [...] quão absurda seria esta avaliação "científica"! Que se haveria apreendido, compreendido, conhecido de uma melodia assim apreciada?

O fato é que a mensuração não é substituta do julgamento, como lembra Mintzberg (2009). No caso das universidades, isso é relevante especialmente pelo fato da essência do trabalho acadêmico possuir natureza qualitativa e, por essa razão, estar sujeito não a uma quantificação racional, mas à interpretação e ao julgamento humano quanto à qualidade do trabalho, bem como quanto à relevância e legitimidade junto à sociedade.

\section{Revertendo o quadro}

Um dos grandes mistérios é conhecer como elementos valiosos, como inteligência, conhecimento, curiosidade intelectual, sociabilidade, integração, urbanidade, cidadania, tão importantes para os indivíduos e para a sociedade, são integrados no ambiente universitário, de modo a possibilitar que as universidades realmente cumpram seu papel educacional e social - transformar seres humanos em profissionais e cidadãos orientados por princípios éticos que lhes possibilitem viver e contribuir para uma vida melhor em uma sociedade melhor, mais justa e menos desigual. 
A necessidade dos gestores acadêmicos assumirem um novo comportamento implica o uso pleno de sua autonomia profissional, liderança e autoridade, assumindo riscos e responsabilidades para empreender a administração exigida pelas universidades nos dias atuais. Essa nova postura tem sido sistematicamente rechaçada pelo predomínio das abordagens empresariais, como planejamento estratégico, balanced scorecard, empowerment, benchmarking, melhoria contínua da qualidade, entre outras. Elas representam modismos e práticas gerenciais ultrapassadas, inadequadas, voltadas ao mercado e, portanto, ineficazes no contexto acadêmico. Muitas dessas abordagens são legitimadas por administradores e consultores mais preocupados com recursos, produtividade e eficiência que com a qualidade da educação oferecida, aprendizagem dos alunos e relevância da produção intelectual e científica dos professores.

O resgate de boas práticas gerenciais acadêmicas integra esse novo quadro de inovação gerencial. Refere-se, aqui, ao resgate das boas práticas adotadas em sala de aula, nos laboratórios, na inovação curricular e na forma de incrementar a qualidade do ensino e da aprendizagem com resultados efetivos para o melhor desempenho da organização. Deve-se aproveitar as boas práticas e novos e confiáveis estudos científicos que têm por foco o trabalho nas organizações ao qual se refere Keller (1983).

Muitas dessas práticas decorrem de iniciativas bem-sucedidas no campo da administração acadêmica, que introduzem inovações e melhorias nas atividades, com resultados relevantes para a gestão dos processos de ensino-aprendizagem e pesquisa. Certamente, essas práticas não possuem o brilho e a fama das abordagens empresariais disseminadas em seminários, livros e trabalhos de consultoria modelados para as organizações "máquina", mas são mais compatíveis com a realidade de organizações "profissionais", focadas no conhecimento e na aprendizagem, caso das universidades.

Nesse particular, é importante refletir sobre a alegoria utilizada por Karl Weick (2001) ao relatar dois casos que resultaram em desastre, com a morte de bombeiros. Estes combatiam incêndios em florestas e, por estrita obediência às regras e práticas arraigadas, resistiram a largar suas ferramentas para se salvar. $\mathrm{O}$ autor traz a alegoria para a administração educacional e sugere que os gestores abandonem regras cujos resultados são duvidosos ou até ameaçadores.

Finalmente, cabe destacar que os gestores acadêmicos, como gestores intuitivos, aos quais se refere Birnbaum (2000), necessitam aprender a lidar com o fato de que não existem modelos ou ferramentas disponíveis, no repertório da Administração, para tratar questões como a mensuração da produção acadêmica e a análise do valor agregado. Os medidores, quando existentes, não são confiáveis por não mensurar a essência do objeto analisado.

\section{Comentários Finais}

A dificuldade de estabelecer padrões para medir a eficácia das universidades é uma barreira que desafia avaliadores e especialistas no trabalho acadêmico. Ainda não foram encontradas fórmulas para avaliar o impacto do Ensino Superior em indivíduos e na sociedade.

Apesar de não haver fórmulas adequadas para a medição do esforço acadêmico, existe a necessidade de ampla prestação de contas - accountability - aos grupos externos que apoiam as organizações públicas e privadas. Para isso, é importante que essas organizações projetem uma imagem positiva. Como todas as instituições sociais, as universidades necessitam de legitimidade para validar sua existência e garantir sustentabilidade (MEYER e ROWAN, 1977). A avaliação atende aos objetivos de legitimação, ao oferecer informações aos grupos externos sobre o funcionamento institucional e o desempenho nos campos educacional, social, político, ético e moral.

Ocorre que a diversidade nas organizações acadêmicas manifesta-se não só pela presença de professores e alunos com perfis, interesses e comportamentos distintos, agrupados em unidades específicas, mas, também, 
aponta diferenças dentro dessas unidades e entre elas. Nas universidades, percebe-se que a qualidade do trabalho não é uniforme, trata-se de um ambiente onde o ótimo, o bom e o ruim convivem lado a lado.

O que se observa é a existência de um sistema de avaliação do Ensino Superior que, imbuído do frenesi da mensuração, impõe uma variedade de critérios de medição que seriam mais adequados a um sistema justaposto, mas que, inadequadamente, vem sendo utilizada em um sistema frouxamente articulado, como são as instituições de Ensino Superior e, em particular, as universidades.

Sem desconhecer a importância dos números, das estatísticas, da linguagem matemática e dos métodos quantitativos, fundamentais para uma adequada gestão, é fundamental ter em mente que, como destaca Lapierre (2005), uma organização pode oferecer um bom produto ou um serviço de qualidade apoiada em uma gestão artesanal, ou seja, uma prática gerencial não alinhada às normas reconhecidas, às regras tradicionais da exatidão, dos processos normativos e das teorias populares predominantes.

A Administração é vista como uma manifestação da racionalidade, contudo as universidades, por suas especificidades, requerem abordagens com sensibilidade para reunir e utilizar seus diversos recursos, de forma criativa e inovadora, sabendo equilibrar o uso da razão, reconhecidamente limitado, com aspectos subjetivos, como a intuição e valores éticos fortemente presentes nas ações humanas.

\section{Referências}

BALDRIDGE, J. V. Power and conflict in the university: research in the sociology of complex organizations. New York: Willey, 1971.

BECKER, H. S. Falando da sociedade. Ensaios sobre as diferentes maneiras de representar o social. Rio de Janeiro: Zahar, 2009.

BIRNBAUM, R. How colleges work. San Francisco, CA: Jossey-Bass, 1989.

BIRNBAUM, R. Managing fads in higher education. San Francisco, CA: Jossey-Bass, 2000.

BOK, D. Universities in the marketplace. Princeton, NJ: Princeton University Press, 2003.

BOULDING, K. In praise of inefficiency. AGB Reports, p. 44-48, jan./feb. 1978.

BOWEN, H. Investment in learning: the individual and social value of American higher education. San Francisco, CA: Jossey-Bass, 1980.

BREWER, D. J.; GATES, S. M.; GOLDMAN, C. A. In pursuit of prestige: strategy and competition in U. S. higher education. New Brunswick, NJ: Transaction, 2002.

CAMERON, K. S. Measuring organizational effectiveness in institutions of higher education. Administrative Science Quarterly, v. 23, n. 4, p. 604-632, 1978.

COHEN, M. D.; MARCH, J. G. Leadership and ambiguity. Boston, MA: Harvard Business School Press, 1974.

ETZIONI, A. Modern organizations. Englewood Cliffs, NJ: Prentice-Hall, 1964.

FORBES, D. P. Measuring the unmeasurable: empirical studies of nonprofit organization effectiveness from 1977 to 1997. Nonprofit and Voluntary Sector Quarterly, v. 27, n. 2, p. 183-202, 1998.

GHOSHAL, S. Bad management theories are destroying good management practices. Academy of Management Learning \& Education, v. 4, n. 1, p. 75-91, 2005. 
GOIS, A. Ênfase em testes empobrece a qualidade da educação, diz Nobel. Entrevista com James Heckman. Folha de S. Paulo, p. A12, 17 out. 2011.

JULIATTO, C. I. A universidade em busca da excelência. Curitiba: Champagnat, 2005.

KELLER, G. Academic strategy: the management revolution in American higher education. Baltimore, MD: Johns Hopkins University Press, 1983.

LANGLEY, A. Between "paralysis by analysis" and "extinction by instinct”. Sloan Management Review, v. 36, n. 3, p. $63-75,1995$.

LAPIERRE, L. Gerir é criar. Revista de Administração de Empresas, v. 45, n. 4, p. 108-117, 2005.

MARCH, J. G.; OLSEN, J. P. Ambiguity and choice in organizations. Bryggen: Universitetsforlaget, 1976.

MEYER J.; ROWAN, B. Institutionalized organizations: formal structure as myth and ceremony. American Journal of Sociology, n. 83, p. 340-363, 1977.

MINTZBERG, H. Mintzberg, a note on that dirty word "efficiency". In: MINTZBERG, H. On management: inside our strange world of organizations. New York: Free Press, 1989. 330-334 p.

MINTZBERG, H. The rise and fall of strategic planning. Englewood Cliffs, NJ: Prentice Hall, 1994.

MINTZBERG, H. Managers not MBAs. San Francisco, CA: Berrett-Koehler, 2004.

MINTZBERG, H. Managing. San Francisco. CA: Berret-Koehler, 2009.

NIETZSCHE, F. A Gaia ciência. São Paulo: Companhia das Letras, 2000.

REYNOLDS, G. H. The new school: how the information age will save American education from itself. New York: Encounter, 2014.

SIMON, H. The job of a college president. Educational Record, v. 58, p. 69, 1967.

STACEY, R. D. Complexity and organizational reality. London: Routledge, 2010.

WEICK, K. E. Educational organizations as loosely coupled systems. Administrative Science Quarterly, v. 21, n. 1, p. 1-19, 1976.

WEICK, K. E. Sources of order in underorganized systems: themes in recent organizational theory. In: WEICK, K. E. Making sense of the organization. London: Blackwell, 2001. 32-56 p. 